Artigos

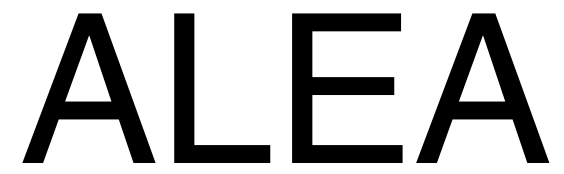




\title{
A TRADUÇÃO: NO LIMIAR ${ }^{1}$
}

\author{
TRANSLATION: IN THE THRESHOLD
}

\author{
Alexis Nouss \\ Cardiff University \\ Cardiff, País de Gales
}

\section{Resumo}

No que diz respeito à sua fundação epistemológica, que permanece frágil, a tradutologia geralmente concebe seu objeto sob a lógica da transferência e da circulação. Se é possível conceder-lhe legitimidade conceitual, uma tal apreensão corre o risco de acarretar uma fetichização ideológica nefasta à percepção da plena dimensão ética do traduzir. Em prejuízo da concepção reinante, é possível repensar a tradução como experiência do limiar, e não da passagem. Enquanto a etimologia do significante francês seuil [limiar] insiste numa empiricidade estática, o vocábulo inglês e o alemão para o termo abarcam uma ideia mais dinâmica e dialetizam a retenção e a mobilidade, possibilitando outra percepção da visada tradu-

${ }^{1} \mathrm{O}$ presente texto tem por base conferência pronunciada no dia 29 de outubro de 2011 no âmbito do Colóquio Traduction et partages: que pensons-nous devoir transmettre?/ XXXVIIe Congrès de la Société Française de Littérature générale et comparée, realizado na Universidade de Bordeaux, e foi precedida do seguinte preâmbulo:

Depois da American Comparative Literature Association e do MLA em 2009, o congresso da SFLGC interroga-se esse ano a respeito das apostas que a tradutologia enuncia - apelo que eu, de minha parte, não recuso. Certamente, sem a virulência que tomou conta da discussão na América do Norte, onde chegamos ao ponto de nos perguntarmos se a tradutologia poderia ou deveria substituir a literatura comparada. Que o sentimento seja de apreensão ou de esperança, é necessário não idealizarmos: a tradutologia não é capaz de forma alguma de salvar ou ressuscitar a literatura comparada, pois ela carrega, de modo similar, indecisões e divisōes internas, enredadas nas suas exclusivas disputas de igrejinhas.

Em segundo lugar, para evocar um horizonte por vezes tempestuoso do comparativismo, creio que o impasse da literatura-mundo, qualquer que seja a sua inflexão (profética ou científica, militante ou sociológica), é o de não reivindicar limiares. A presença e a consciência do limiar, indispensável à visada tradutória, atenua-se para a literatura comparada, que pode estudar objetos desconectados ou sem relação a priori. Em compensação, essa liberdade do comparativismo pode inspirar uma tradutologia inibida por sua obsessão do par primordial, original e texto traduzido. Em outras palavras, fazendo o jogo dos prefixos e notando que na loja dos acessórios disciplinares a literatura comparada escolheu o inter enquanto a tradutologia parte do trans, nós diremos que o trans tem necessidade do inter para que se opere uma troca e não uma simples transferência e que o inter tem necessidade do trans para dinamizar o espaço mediano, em vez de abordá-lo como terra em pousio. Pois há um espaço mediano, aquele que designamos como limiar.

Palavras-chave: Tradutologia; São Jerônimo; Santo Agostinho. 
Mots-clés: Traductologie; Saint Jerôme; Saint Augustin.

Keywords: Tradutology; St. Jerome; St. Augustine.

tória e da relação entre as línguas. No oco matricial de seu encontro, um sujeito pede e recebe a hospitalidade...

\section{Résumé}

Quant à sa fondation épistémologique, au demeurant fragile, la traductologie aborde généralement son objet sous les espèces du transfert et de la circulation. S'il y a légitimité conceptuelle à le faire, une telle appréhension court le risque d'entraîner une fétichisation idéologique néfaste à percevoir la pleine dimension éthique du traduire. Au dam de la conception régnante, il est possible de repenser la traduction comme expérience du seuil, et non du passage. Tandis que l'étymologie du signifiant en français insiste sur une empiricité statique, les termes anglais ou allemand pour seuil retiennent une idée plus dynamique et dialectisent arrêt et mobilité, inspirant une perception différente de la visée traductive et du rapport entre les langues. Au creux matriciel de leur rencontre, un sujet demande et trouve l'hospitalité...

\begin{abstract}
With respect to its epistemological foundation, which remains fragile, tradutology generally conceives its object as subordinate to a logic of transference and circulation. Although possible to concede some conceptual legitimacy to this perception, it carries within itself the risk of an ideological fetichization, harmful to the ability to fully recon the ethical dimension of translation. It is possible to re-think the experience of translation as related to the threshold, not to the passageway. Whereas the etymology of the French word for "threshold" [seuil] insists on a kind of static empiricism, the English and German names transmit a more dynamic idea and dialectize both retention and mobility, thus opening the possibility to understand differently the relation between languages. In the matrixial hollow opened on their encounter, a subject claims and receives hospitality.
\end{abstract}

O Museu de Belas-Artes de Bordeaux abriga uma tela de Pietro Vannucci, conhecido como il Perugino, intitulada $A$ virgem e o menino entre São Jerônimo e Santo Agostinho. ${ }^{*}$ Nesse quadro, típico do Renascimento italiano em termos de tema, trabalho, cenário e decoração, São Jerônimo é facilmente reconhecível pelo traje e pelo chapéu vermelho de cardeal, mesmo que as funçōes e os atributos relacionados ao vestuário só tenham aparecido mais tardiamente. Um critério temporal pouco significativo. A trans-historicidade prevalece, guiando a representação mitologizante. Os tempos antigos são traduzidos para o presente do século XVI, que por nossa vez traduzimos para o nosso. 


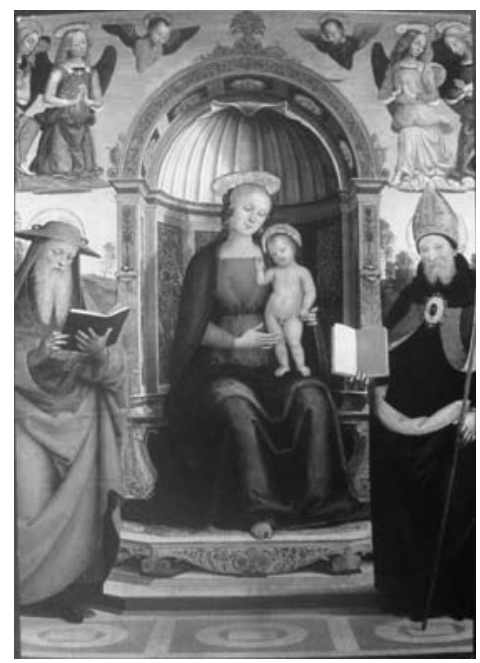

Cada um dos santos tem um livro - topos pictural na iconografia cristã do Renascimento -, mas o contraste entre as duas atitudes e os dois livros é surpreendente. O que Santo Agostinho segura está aberto em direção ao espectador, que vê duas páginas brancas, ao passo que não se vê nada além do dorso do livro que São Jerônimo segura. Santo Agostinho olha direta e serenamente para o espectador, como se o interpelasse, enquanto São Jerônimo, de cabeça baixa, está mergulhado na leitura, parecendo ignorar o entorno. Um livro de texto ausente nos dois casos. Um texto ainda por escrever.

Como interpretar a cena? Sendo os dois personagens suficientemente carregados de valor simbólico, os binarismos dicotômicos interpretativos não faltam: o espírito (Santo Agostinho) versus a letra (São Jerônimo)? O estudo (São Jerônimo) versus o poder (Santo Agostinho)? O Antigo Testamento (São Jerônimo) versus o Novo (Santo Agostinho)? Ou ainda a Torre de Babel (São Jerônimo) versus o Pentecostes (Santo Agostinho), para citar os dois episódios bíblicos ligados à questão da multiplicidade das línguas?

Em vez de opô-las, escolho aproximar as duas figuras e reunilas no espaço, em seu próprio espaço e naquele que elas criam. Será perceptível um espaço utópico entre São Jerônimo e Santo Agostinho, o que seria sugerido pela irrealidade da dupla figura central, sacralizada na alcova luxuosamente esculpida, mas também pelos livros, já que a utopia é ao mesmo tempo discursiva e se apoia num 
texto? Os trajes dos dois santos impedem essa leitura e nos conduzem a uma historicidade bem normatizada. Um espaço específico, portanto, uma dupla triangulação: o par de santos e os dois livros, e, especularmente, os dois livros e o espectador. $\mathrm{O}$ espaço que se dá a ver e que dá a ver não é utópico, ou antes, freia a pulsão utópica que a representação da virgem e a presença dos livros lhe concederiam.

Vamos, então, designá-lo como transtópico, “tópico" tomado no sentido ao mesmo tempo espacial e retórico. O espectador constrói um saber transtópico a partir de sua experiência visual, do mesmo modo que o leitor constrói um saber transtópico ao conectar dois espaços linguísticos e culturais. O tradutor, por sua vez, ativa um saber transtópico ao religar original e tradução. Um texto ausente circula então do livro de Santo Agostinho ao espectador e deste ao livro de São Jerônimo, cujas páginas estamos no direito de supor não serem virgens. Cabe ao espectador escrevê-las. Ou traduzi-las. O que ele pode fazer de duas maneiras que corresponderiam às duas figurações do livro: visto de frente, aberto, e pelo verso.

É possível chamá-las, tomando de empréstimo um léxico contemporâneo ao quadro, translatio e traductio. É no século XVI que o segundo termo aparece nas línguas romanas para concorrer com o primeiro, já conhecido pela latinidade. Os dois rivalizam na categoria sócio-escriturária de "transferência cultural". Uma questão de partilha e de transmissão.

O que nos diz nossa historicidade sobre o díptico translatiol traductio e o que este nos diz sobre nossa historicidade? Ele é proveniente da era medieval, com a qual a nossa era, dita da globalização, merece ser comparada. Ambos enfrentam o mesmo dilema: como formar um todo sem sacrificar a integridade das partes? A modernidade, a partir das Luzes, encontrou a solução sob a forma da divisão dos Estados-nação e de suas fronteiras geolinguísticas. Hoje o modelo está gravemente em crise e as identidades, assim como os pertencimentos, padecem de incerteza.

Entretanto, a comparação vem nos inquietar a respeito de outro ponto: a época medieval e a nossa confrontam-se com a questão da transferência do saber, da circulação dos conhecimentos - a circulação das informações suscita outra problemática - que se modificam com uma intensidade anteriormente desconhecida. 
Translatiol traductio remetem a dois modos de transferência cultural, antes de eventualmente designarem duas práticas tradutórias.

Breve esboço: translatio descreve um processo passivo, realizado em num nível geral e coletivo; traductio descreve um processo ativo, produzindo uma responsabilidade individual que recai sobre uma operação singular. Translatio se compreende como um efeito; traductio, como uma ação. Translatio remete a communio, a visada de uma identidade comum que apaga as delimitações e aspira à partilha, enquanto traductio visa à communicatio, à necessidade de dar, de trocar (bens e, posteriormente, mensagens) para além dos limites, e aspira à transmissão. Cultura comum (translatio) versus culturas em comum (traductio).

Voltando a nossos santos, Agostinho remete à translatio, com o livro aberto, de acordo com a ampla inspiração de sua produção literária: suas Confissões alimentam-se das histórias do povo judeu, dos gregos e romanos, da literatura greco-latina, dos dois Testamentos e dos Pais da Igreja. Jerônimo defende uma relação de traductio com sua fonte, a Bíblia hebraica, diante da qual ele adota uma estratégia de proximidade formal.

Se translatio e traductio identificam as respectivas posturas de Santo Agostinho e de São Jerônimo em matéria de transferência textual, as duas noções apontam também para as posições dos dois no quadro de Perugino. Eles se posicionam diante da Virgem e do Menino como diante de um limiar, na medida em que pertencem ao espaço sagrado, ao espaço do sagrado, sem nele penetrar. No limiar do sagrado e dele separados por dois degraus, no limiar do espaço em que sopram o Espírito Santo e o logos, eles encarnam dois modos de posicionamento no limiar do sentido. Este brilha no meio da tela, como testemunhando o gesto do Menino Jesus, abençoando o espectador e o mundo. No limiar do verbo, duas maneiras de recebê-lo, dois modos de traduzi-lo. Santo Agostinho ignora o limiar dirigindo-se ao mundo, São Jerônimo concentra-se sobre ele ao voltar-se para o livro. A tradução: no limiar.

A frequência da metáfora da ponte e a insistência sobre a ideia de passagem nas análises que tratam da tradução revelam uma tendência que chamaremos de cinecentrismo, e que, mesmo sendo antiga, pode ser mais bem compreendida na paisagem ideológica das sociedades contemporâneas que privilegiam os princípios de movimento e de circulação para descrever sua natureza e funcionamento, marcadas pelo desenvolvimento exponencial das trocas e dos 
transportes em escala planetária, pela importância das migrações e pelos avanços tecnológicos da telecomunicação. Em particular, o conjunto das realidades econômicas e culturais que recobre o fenômeno designado como globalização concede um papel maior à tradução, reputada a responder com uma fluidez e uma rentabilidade máximas às necessidades de transferência e de comunicação. Todavia, não é certo que a tradução se beneficie dessa concepção cinética, cujo utilitarismo reforça o estatuto secundário que ela frequentemente recebeu em detrimento de suas capacidades criadoras, sobre as quais insiste, por sua vez, a tradutologia contemporânea.

Isso nos convida a refletir sobre o que se passa à margem do processo tradutório ou no limiar da tradução. Com efeito, o pensamento do limiar é central para compreender o da tradução, e vice-versa, pois, contrariamente à concepção reinante, a tradução não é apenas passagem, ela tanto oferece a experiência do limiar como nos permite interpretá-lo de outra forma. Dizer que a tradução está no limiar significa dizer que o traduzir atrai sobre seu gesto toda a ambiguidade da margem, a indecidibilidade que ela introduz entre o fora e o dentro e, aqui, entre o texto original e o texto traduzido. Contra as teorias e, sobretudo, a pedagogia, que ainda se debatem para intensificar a importância de um em detrimento do outro, qualquer que ele seja, a postura paratradutológica - o termo "paratradução" surgiu dos trabalhos da Escola de Tradução da Universidade de Vigo, à qual sou associado - convida a considerar aquilo que ultrapassa as duas entidades textuais e a medir suas exigências axiológicas.

A metáfora da passagem desperta a desconfiança por dois motivos: uma passagem bem sucedida, realizada, é impossível, e o desejo de que assim seja reflete uma pulsão dominadora decorrente de um orgulho culpado. Substituí-la pela imagem do limiar, revelando o que ela oculta de negativo, introduz uma postura que conjuga modéstia e potência. Lembremos o conto de Kafka, "Vor dem Gesetz", "Diante da lei". ${ }^{2}$ Nenhum antagonismo conceitual permanece entre limiar e passagem: um limiar é um lugar de passagem e, portanto, acolherá uma multiplicidade de movimentos,

\footnotetext{
${ }^{2}$ Elaborei uma leitura tradutológica do conto no artigo "Vor dem Gesetz: la porte du traduire. D'une théorie de la traduction chez Kafka” ["Vor dem Gesetz: a porta da tradução. Para uma teoria da tradução em Kafka”], TTR, vol. V, n.2, Montréal, 1992.
} 
mas esses não devem ocultar a importância do limiar enquanto tal, nem fazer menção a ele apenas numa perspectiva sequencial (o limiar como lugar para a passagem). Se o francês seuil ${ }^{3}$ remete antes ao peso do solo, o inglês threshold guarda em thresh a ideia dinâmica da pressão do pé e dialetiza a suspensão (hold) e a mobilidade, similarmente ao campo semântico do alemão schwelle. Uma incerteza (passar ou não) que o espanhol umbral carrega, a indistinção, a indecisão, ou antes, a suspensão da decisão - como traduzir? -, o pragma grego, ao mesmo tempo coisa e acontecimento, o que mostra que toda tradução, como toda enunciação, é pragmática, a literária sendo apenas seu modo mais intenso.

A noção de limiar apresenta com vantagem a ideia de um espaço limitado capaz de acolher um número ilimitado de trajetórias de subjetivação. Um quadro fixo para dar conta de uma multiplicidade de ações, assim como a imagem cinematográfica, cujo retângulo sobre a tela acolhe a infinitude de movimentos da vida. $\mathrm{O}$ tradutor conhece a embriaguez similar de uma multiplicidade de escolhas tradutórias possíveis diante do texto original, o que não é sem consequências. Confrontado com a estranheza do original, ele deve encontrar um espaço em que não sucumbirá à alteridade, cuidando também para não lhe impor o cabresto de suas idiossincrasias linguísticas e culturais. Tal exercício é mal sucedido se a tradução pressupõe a existência de territórios linguístico-culturais delimitados e se for definida como passagem de um $a$ outro. A passagem de um no outro, ao contrário, evocada pela experiência do limiar, permite sua concepção adequada: dois territórios móveis em vez de uma mobilidade percorrendo-os, dois territórios nômades, mais que um nomadismo atravessando-os. Uma imagem a ilustra, o moiré que designa um efeito visual presente num tecido ou na superposição de duas tramas metálicas. O léxico do grafismo eletrônico adotou-o em seguida. Note-se que o termo carrega uma bela história transcultural, já que, proveniente do árabe, atravessou os espaços francófono e anglófono. No moiré, duas superfícies se encontram e criam uma terceira, assim como a tradutologia adotou a ideia de que duas línguas em presença uma da outra produzem uma terceira, nova a cada tradução, e no limiar da qual existem as duas primeiras. Uma terceira língua imiscuindo-se entre língua traduzida e língua tradutora, seja essa língua terceira fantasmática

\footnotetext{
${ }^{3}$ Limiar, soleira (N. do T.)
} 
* (BENJAMIN, Walter. Paris, capitale du XIXe siècle. Le livre des passages.Tradução de J. Lacoste. Paris: Le Cerf, 1989: 512-513.)

* (BENJAMIN, Walter. "Sur le langage en général et sur le langage humain". In: OEuvres I. M. de Gandillac e R. Rochlitz (trad.). Paris: Folio/ Essais, 2001: 157.) ou um idioma registrado: o latim para Chateaubriand, tradutor de Milton; o alemão para Klossowski, tradutor de Virgílio; ou ainda Tourgeniev, dando recomendações em francês para seus romances em russo a seu tradutor inglês.

A espacialidade capaz de dar conta desse fenômeno de deslocamento territorial pertence ao que se apresenta como uma zona, realidade de uma semantização de caracteres opostos: divisão rigorosa (zona militar, zona de habitação, "zona do euro"...) ou delimitação incerta (a zona dos subúrbios urbanos), regulação estrita ou fora da lei, segurança ou ameaça. ${ }^{4}$ Em razão de uma tal ambivalência a zona precisa ser abordada por limiares, e o próprio limiar, limitando o ilimitado, assemelha-se à zona. É essa a definição que lhe dá Walter Benjamin, ao preço de uma etimologia arriscada: "É preciso distinguir cuidadosamente o limiar da fronteira. O limiar (schwelle) é uma zona. As ideias de variação, de passagem de um estado a outro, de fluxo, estão contidas no próprio termo schwellen (inchar, inflar, dilatar) e a etimologia não deve negligenciá-las". 5

* A análise é aproximável de sua definição de tradução no ensaio sobre a linguagem: "A tradução é a passagem de uma língua a outra por uma série de metamorfoses contínuas. Ao atravessá-las, a tradução percorre contínuos de metamorfoses, não regiōes abstratas de similitude e semelhança".* Por essa serialidade que tem então como consequência criar uma zona sob a forma de uma sequência de limiares, traduzir significa manter-se sempre no limiar, e de maneira bilateral: que uma língua seja o/ esteja no limiar da outra e vice-versa.

A zona traça um espaço sem princípio de continuidade que religaria os elementos nele contidos em virtude de uma autoridade exterior ou transcendente, pois a relação entre eles é regida apenas por sua concomitância. $\mathrm{O}$ processo tradutório situa original e tradução numa zona paratraducional, ${ }^{6}$ onde os dois textos abdicam

\footnotetext{
${ }^{4}$ Diante da recente atualidade, não se sabe mais com certeza se a "zona do euro" pertence à primeira ou à segunda acepção.

${ }^{5}$ Uma versão anterior do segmento inclui os termos de transição e de mutação (p. 852).

${ }^{6}$ Dois textos revelaram, nesse sentido, a importância de tal esclarecimento: o artigo de 1991 de Mary Louise Pratt, "Arts of the Contact Zone" (em Profession, 91, New York: MLA) e o livro de Emily Apter, The translation zone (Princeton and Oxford: Princeton University Press, 2006). É significativo que uma das recém-lançadas revistas de tradutologia se denomine Translation Spaces (publicada por John Benjamins).
} 
de sua autonomia para que jorrem do encontro entre eles formas e significações diferentes, suscitando, por sua vez, novas interpretações. Citemos como exemplo, precisamente, o poema "Zone", de Apollinaire, que conheceu várias traduções em inglês. Uma delas aparece em 1950 e é assinada por um certo Samuel Beckett. O original de 1913 está enraizado na modernidade europeia; a versão de Beckett se situa na posteridade. Antes da Primeira Guerra Mundial, depois da Segunda. "Soleil cou coupé", o verso final, é traduzido por "Sun corseless head" [Sol cabeça sem cadáver].* Ali onde Apollinaire insistia em uma cabeça perdida, uma Europa sem direção, Beckett insiste em um corpo desaparecido, uma Europa sem realidade, ao mesmo tempo em que com o vocábulo arcaizante corse, assonante com "cou", ele inscreve a história em sua tradução ${ }^{7}$ e assim explica sua escolha. Zona de trans-historicismo de uma responsabilidade tradutória autêntica diante do meta-historicismo das aproximações semânticas da tradução ou do historicismo das abordagens filologizantes.

É significativo que o título em inglês da obra Seuils, de Gérard Genette, seja Paratexts. Thresholds of Interpretation, * com o subtítulo deslocando a aposta da teoria literária, quadro inicial da análise Genette, para a hermenêutica, sobre a qual sabemos que procura, a partir da linguística, uma segunda instância fundadora maior para a tradutologia. Assim como a hermenêutica interroga a posição do intérprete, evocar o limiar da tradução leva a refletir sobre o lugar do tradutor e ao mesmo tempo sobre a posição da tradução. Constatar-se-á o quanto a palheta de Genette se torna espacializante quando ele introduz a noção de paratexto: a limiar, acrescentam-se vestíbulo, zona, borda, franja. Ora, esse cuidado com a localização textual, negligenciado pela tradutologia, não é anódino diante de algumas práticas tradutórias: as Bíblias poliglotas do Renascimento ou a publicação sistemática em edição bilíngue de traduções de certos autores, Paul Celan, por exemplo. "Poliglota"

\footnotetext{
${ }^{7}$ Inscreve-a também por meio de um enjambement: "C'est l'étoile à six branches/ C'est Dieu qui meurt le vendredi et ressuscite le dimanche" traduzido para: "It is the six-branched star it is God/Who Friday dies and Sunday rises from the dead". (Ibidem:109)

${ }^{8}$ Sobre as traduções da obra de Paul Celan, conferir meu livro Paul Celan. Les lieux d'un déplacement (Lormont: Éditions du Bord de l'Eau, 2010). A propósito, é perceptível uma prática editorial de mesma natureza: a integração das traduçôes feitas por um autor no seio de sua obra publicada, quer essa escolha seja desejada por ele ou não. É o caso de Celan, dos poetas franceses Armand Robin
}

* (Samuel Beckett. Collected Poems in English and French. Londres: John Calder, 1977: 121.)

* (GENETTE, Gérard. Seuils, Paris, Seuil, 1987; GENETTE, Gérard. Paratexts. Thresholds of Interpretation. Jane E. Levin (trad.). Cambridge/ New York, Cambridge University Press, 1997.) 
* (ESTEBAN, Claude. Poèmes parallèles. Paris: Galilée, 1980.) ou "bilíngue", os dois termos carregam uma parcela de ambiguidade, uma vez que vêm, nesse caso, lançar uma suspeita sobre a noção de original, oferecido ao leitor do mesmo modo que a tradução, lembrando que o afastamento da tradução em relação ao original é um fenômeno submetido à variação histórica9 e que não poderia ser tomado como um absoluto. Reconduzi-los ao limiar um do outro se compreende por essa iluminação.

É preciso considerar o limiar tradutório como ligado à própria natureza do ato de tradução, que encontra sua legitimidade por seu estatuto à margem do original, sem que isso implique qualquer inferioridade a não ser que esta seja ideologicamente decidida. Importa ser consistente em relação a essa condição fundamental e, consequentemente, desmarginalizar a margem no processo de tradução, aceitando que uma ética do limiar guie nossa prática tradutória. Permanecer no limiar sem fazer dele um preliminar, o preâmbulo à passagem, à penetração na língua e no texto estrangeiro. Pois a espera não define o limiar, assim como a função, o skopos ou o querer-dizer, não dizem a verdade do traduzir. Esses termos, de cotação elevada no mercado didático da tradução, servem talvez como fins pedagógicos, mas não dizem nada sobre a natureza do fenômeno. Permanecer no limiar convoca uma forma de tradução que não é passagem, e sim deslocamento. Um deslocamento não é uma passagem. Uma passagem se faz de um corpo de um contexto para outro, com todos os riscos de manipulação e de dominação; o deslocamento implica que o corpo carregue com ele o contexto e o faça reencontrar o outro contexto - o que ilustra a estética do moiré-, garantindo a plenitude do movimento. Pois em um verdadeiro encontro, cada um permanece no limiar do outro, respeitando-lhe a existência e o percurso. Assim, toda tradução, em virtude dos limiares tradutórios que ela pressupõe, seguirá uma trajetória paralela à do original, tomando de empréstimo como qualificativo o título da coletânea de poemas traduzidos por Claude Esteban, Poemas paralelos. ${ }^{10 *}$

\footnotetext{
e Philippe Jaccottet, ou ainda de Samuel Beckett.

${ }^{9}$ À moda do estatuto da tradução que, por exemplo, a Idade Média considerava como uma via dentre outras de circulação de escritos, sem conceder uma importância particular à passagem interlinguística em sua definição.

${ }^{10}$ Claude Esteban participou em 1986 das Assises de la traduction littéraire com uma comunicação intitulada "Territoires, frontières et partages" (In: Actes des troisièmes assises de la traduction littéraire. Arles: Actes Sud, 1987, pp. 30-45).
} 
Apropriando-nos do léxico do cinema, diremos que a tradutologia evoluiu positivamente desde os seus inícios disciplinares ao interrogar o que está em jogo nas relaçôes entre campo e contracampo (o autor e sua obra, a saber, o tradutor e/ ou o leitor-receptor da tradução), mas devendo conceder atenção semelhante ao fora-de-campo. Esse último termo designa toda a espacialidade que não aparece na representação fílmica, tudo o que a cerca materialmente, à margem, no limiar da imagem, mas também tudo o que se passa ali e que o espectador pode apenas adivinhar. Ora, a imagem cinematográfica existe apenas por sua apresentação em um quadro precisamente cortado pelo fora-de-campo. Se essa regra vale para todo filme, alguns diretores fazem dela um princípio de criação maior. Isso tanto vale para todo um gênero, o cinema fantástico ou de horror, que se nutre dela substancialmente, quanto para obras individuais como as de Hitchcock, Antonioni ou Godard. Se o fora-de-campo ilumina especificamente suas respectivas estéticas, estas, em revanche, demonstram a necessidade de considerá-lo integralmente para qualquer obra cinematográfica. $\mathrm{O}$ mesmo é válido para o texto traduzido que extrai seu valor de tudo o que cerca sua produção e que a recepção não deve apagar.

O fora-de-campo existe em pintura sob a forma do além do quadro pictural. Ele não é o tema de uma das obras-primas mais eminentes de sua história, o quadro de Velasquez, Las Meninas? Nele, um pintor pinta um pintor pintando o ato de pintar. Ora, a época que acolhe essa dobradura pictural do protegido de Felipe IV é precisamente aquela, a idade clássica, da qual diz Foucault:

Pois o que mudou na primeira metade do século XVII e por muito tempo [...] foi o regime inteiro dos signos [...]; foi aquilo que, dentre tantas outras coisas que sabemos ou que vemos, os erige de súbito como signos; foi seu próprio ser. [...] A partir da idade clássica, o signo é a representatividade da representação enquanto ela é representável.*

Ora, o que permite a representatividade, definindo a natureza e a função dos signos, define uma outra condição linguística, a traduzibilidade. Que uma ideia remeta a uma percepção, a uma sensação ou a outra ideia, que uma possa representar a outra implica e significa que elas são traduzíveis, que elas podem passar de um regime de significação a outro, modificando-se sem se perderem. A idade clássica uniu razão e tradução, a primeira exercendo um modo de inteligibilidade fundado sobre a segunda: o que pode ser tradu-

* (FOUCAULT, Michel. Les mots et les choses. Paris: Gallimard, 1967: 72 et 79.) 
* (LEFEVERE, André. Translation/History/Culture. A Sourcebook. London and New York, Routledge, 1992: 64.)

* (BENJAMIN, Walter. "L'abandon du traducteur" ["Die Aufgabe des Übersetzers"]. Laurent Lamy e Alexis Nouss (trad.). TTR, vol. X, no. 2, 1997: 14-15.)

* (Ibidem: 21,22 et 25 , respectivamente.) zido é racional. Não é de se espantar que Alexander Pope, no prefácio à sua tradução da Ilíada de 1715, utilize a metáfora do fogo, familiar aos pensadores do classicismo, de Descartes a Berkeley, já que para eles a racionalidade é compreendida como algo luminoso: "Se às vezes há Escuridão, frequentemente há $L u z$ na Antiguidade, e nada a preserva melhor que uma Versão quase literal. [...] É indubitável que o Fogo do poema é aquilo a que um tradutor deveria principalmente atentar, porque é ele que corre o risco de desaparecer na operação". ${ }^{11}$ *

Do romantismo alemão e da hermenêutica de Schleiermacher ao pensamento de Walter Benjamin, o esforço teórico vai incidir sobre uma essencialização da traduzibilidade como condição linguística autônoma, tendência da qual curiosamente se afastará uma tradutologia contemporânea, denunciando o "translationese" difundido no mercado da tradução profissional em vez de se congratular com a emergência de uma língua-tradução vindo concorrer com as línguas-de-tradução.

Assim, para Walter Benjamin,

é preciso constatar que alguns conceitos de ordem relacional conservam sua verdadeira significação, e provavelmente o seu melhor, quando se faz de saída a economia de toda referência exclusiva ao homem. [...] Desse modo, restaria a avaliar a traduzibilidade [Übersetzbarkeit] das faturas linguísticas, mesmo que elas sejam intraduzíveis para os homens.*

Definitivamente metafísico, o pensamento de Benjamin sobre a linguagem vincula-se à teologia - uma teologia neutralizada e secularizada, já que empregada como plano de entendimento fora de qualquer vínculo religioso dogmático - para encontrar seu espaço crítico e nele construir uma consideração sobre a tradução situada por consequência em um fora-de-campo especulativo maximal.

Numa escala estrutural mais reduzida, a noção de margem figura na rede metafórica de seu ensaio sobre a tradução por meio de várias metáforas tomadas de empréstimo ao semantema da liminaridade: o fruto e a casca, o manto real, a borda da floresta (e o eco da língua original), o muro e a arcada.* Uma articulação essencial do aparelho conceitual necessita dela do mesmo modo,

\footnotetext{
${ }^{11}$ No original: "If there is sometimes a Darkness, there is often a Light in Antiquity, which nothing better preserves than a Version almost literal. [...] It is not to be doubted that the Fire of the poem is what a Translator should principally regard, as it is most likely to expire in his managing".
} 
aquela que esclarece o princípio da "pura língua", ou seja, o que em toda língua aponta para a linguagem fora da comunicação de um sentido : "Redimir em sua própria língua essa pura linguagem, exilada na língua estrangeira, libertá-la, graças à reescrita [Umdichtung], de estar cativa na obra, tal é a tarefa do tradutor".* Umdi* (Ibidem: 26.) chtung que o alemão emprega sobretudo pela transposição intralinguística - redoar um autor antigo a um estado mais recente da língua -, acrescentando o prefixo "um" que, além de significar uma mudança de lugar ou estado, convoca a ideia de um ambiente espacial (em torno de), isto é, de um espaço liminar. ${ }^{12}$ Além disso, fortleben, um dos dois termos (junto com überleben) que Benjamin utiliza para exprimir seu tema central da sobrevida da obra pela tradução, apresenta a partícula fort, cuja significação de continuação ou de prolongamento, aqui compreendida temporalmente, toca o campo semântico do suplemento e consequentemente da borda. A função de sobrevida situa a tradução sob a lógica do por-vir que é também a que rege a temporalidade do limiar. Que o limiar seja o lugar do por-vir não o desvaloriza; ao contrário, seu valor é o da abertura ao que virá, contanto que nos ofereça um único acesso a ele, uma única percepção, uma vez que o por-vir, em sua verdade, deve sempre continuar a sê-lo e então permanecer marcado pela incerteza. Assim é o processo tradutório que não pode jamais vangloriar-se de uma versão definitiva.

O ensaio publicado em 1923 como prefácio à tradução de Benjamin dos Quadros parisienses de Baudelaire ocupa então uma posição no limiar da obra traduzida. Entretanto, já foi notado que o texto não se qualifica como prefácio, já que ele não trata do que pretende introduzir, não fazendo nenhuma consideração ao poeta nem aos poemas. Se tal autonomia afasta-se da função de um prefácio e lhe confere antes a função de um ensaio, o texto, em revanche, não cede quanto ao seu papel de limiar textual. ${ }^{13}$ Do mesmo modo que um limiar faz perceber indistintamente o que está em questão no espaço contíguo, as reflexões de Benjamin fazem eco a uma temática central dos Quadros parisienses, a saber, a possibilidade

\footnotetext{
${ }^{12}$ Essa forma de tradução qualifica, por exemplo, as traduções de Hölderlin, sobretudo do teatro de Sófocles. Ver STEINER, George. Après Babel. Une poétique $d u$ dire et de la traduction (trad. L. Lotringer), Paris, Albin Michel, 197: 302.

${ }^{13}$ Razão pela qual, ainda que o texto seja apresentado como "Vorwort" ou "Vorrede" (prefácio e prólogo), em nossa tradução escolhemos para o subtítulo a palavra "Prolegômenos", uma exposição preliminar com os princípios de um corpus de conhecimentos ou reflexões (ver "L'abandon du traducteur", pp. 13 et 30).
} 
* (BAUDELAIRE, Charles. CEuvres complètes. Paris: Gallimard, coll. "La Pléia$\left.\mathrm{de}^{\prime \prime}, 1967: 97.\right)$

* (LEFEVERE, André. Translation/ History/ Culture. A Sourcebook. London and New York: Routledge, 1992.)

* (ROBINSON, Douglas. Western Translation Theory. From Herodotus to Nietzsche. Manchester: St Jerome Publishing, 2002 [1997].) de encontrar no presente traços do passado e de restaurar-lhe o brilho pelo viés de um olhar poético redentor: a primavera no inverno, uma rainha numa mendiga, a velha Paris na nova cidade, a mulher ou a mãe na velhice... O primeiro termo é, graças ao poema, traduzido no segundo. Se nos lembrarmos do conjunto de imagens do ensaio, não poderemos, a partir dele, permanecer insensíveis ao seguinte verso do poema "Rêve parisien": "Babel d'escaliers et d'arcades" ["Babel de escadas e de arcadas"],* que parece apreender o pensamento benjaminiano sonhando a tradução num cenário barroco de múltiplos limiares.

Apresentado assim, o ensaio segue, em última análise, o trilho de uma longa tradição, louvando o uso paratextual na exposição das teorias da tradução, o que sustenta a legitimidade de nossa proposição epistemológica. As antologias o demonstram facilmente: no volume Translation/ History/Culture, ${ }^{*}$ um terço dos textos são provenientes de prefácios a traduções, enquanto a obra se detém no início do século XX. No volume Western translation studies. From Herodotus to Nietzsche, ${ }^{*}$ que conta com o dobro de entradas, a proporção é similar. Levando em conta os outros paratextos (cartas ou ensaios) escritos paralelamente à redação ou à publicação de traduções, a proporção ultrapassa a metade dos textos citados e se eleva a dois terços, caso sejam incluídas as críticas de traduções. Lembremos que uma das maiores reflexões sobre a tradução no século XX, a de Nabokov, é apresentada no prefácio, no epílogo e na massa oceânica de comentários que ele acrescenta a sua tradução do Oneguin de Poushkin, o próprio romance em verso integrando a tradução em sua fatura escriturária e inspiração temática.

Se o espaço paratextual se revela um lugar privilegiado para que a tradução seja pensada - para que ela própria se pense, como diríamos incluindo a margem na continuidade que ela assume com o texto -, é porque o exercício da tradução apresenta de saída uma dimensão reflexiva, um pensamento de si e sobre si, que o paratexto, "entre o dentro e o fora" do texto, vai abrigar naturalmente, pois ele compreende uma distância sem afastamento, uma separação sem ruptura. Afinidade entre tradução e paratextualidade, porque traduzir implica de saída criar uma margem - e colocar-se à margem - em relação à sua própria língua e à sua própria cultura para acolher as do outro texto, tanto quanto fabricar uma margem diante deste para que ele não imponha sua dominação total. Antes de estar do outro lado do espelho - de se transladar para ali -, Alice 
deve estar diante dele, e o consolo da lareira que o sustenta configura um limiar.

Ignorar a margem seria no mínimo impróprio - ou... paradoxal - segundo uma tradutologia que assenta sua legitimidade na recusa à secundariedade habitualmente concedida à tradução. Além disso, a marginalidade não está marcada pela mesma inferioridade que se supõe na secundariedade. $\mathrm{O}$ que pode ser notado numa observação espacial evidente: a margem não aparece depois, ela se manifesta em primeiro lugar. Toda chegada se faz pela margem. A abordagem paratradutória encontra desse modo as exigências do pensamento liminar ou do pensamento-da-fronteira que demarcam uma importante orientação da reflexão contemporânea. ${ }^{14}$

O estrangeiro não surge do exterior, mas da margem. Na exterioridade de seu fora, ele próprio é outro, um outro semelhante, não ameaçador. É apenas no limiar, ao tocar o limiar, ao chegar à beira do limiar para nele deter-se que ele se torna portador do perigo que o caracteriza e funda sua estranheza. De forma análoga - compreendido o clima de ansiedade que a operação produz -, original e tradução apenas adquirem seus respectivos estatutos quando um está situado no limiar do outro. Sem essa contiguidade eles são apenas dois textos cuja autonomia não é problemática e não pode ser problematizada.

Donde decorre, ao contrário, que a hospitalidade, o acolhimento do estrangeiro, se exerce somente na margem, quando há margem. O episódio bíblico em que Abraão recebe a visita dos anjos anunciando-lhe a gestação inantecipável de Isaac - como toda criança, imagem exemplar do Outro cuja vinda é imprevisível, o que a qualifica como um acontecimento - situa o patriarca "na entrada de sua tenda" (Gênesis, 18: 1) e o comentário rabínico faz dele a imagem do acolhimento do estrangeiro. ${ }^{15}$

O cristianismo retomou a associação entre um espaço liminar e a promessa divina de gestação. Basta evocar as numerosas

\footnotetext{
${ }^{14}$ Ver meu Plaidoyer pour un monde métis. Paris: Textuel, 2005, chapitre 2.

${ }^{15}$ É sobre outro limiar que o episódio da libertação do Egito se apresenta, uma vez que um signo sobre os pórticos e o lintel das portas assinala a casa dos hebreus e os preserva da morte que atinge os recém-nascidos durante a décima praga (Exodo, 12: 1-28). Quanto a Moisés, ele permanecerá no limiar da terra prometida sem nela entrar (Deuteronômio, 32: 48-52 e 34: 1-8; e Números, 20: 7-12), um tema que percorrerá a tradição judaica e que segue a própria lógica da promessa: realizada, ela deixa de existir. $\mathrm{O}$ messias também não deve chegar, para conservar a força do que promete.
} 
* (CACCIARI, Massimo. L'ange nécessaire. M. Raiola (trad.). Paris: Bourgois, 1988: 11.)

* (RICOEUR, Paul. Sur la traduction. Paris: Bayard, 2003: 20.) anunciações da pintura ocidental, notadamente as do século XV e XVI, em que Gabriel interpela Maria diante de um pórtico com finas colunas. Por sua vez, a tradição corânica retoma a ideia na surata 19, versículo 16, que apresenta Maria, escondida atrás de um véu, acolhendo o anjo e delimitando assim um espaço de separação, um limiar.

Ocupar um espaço que precede outro distingue a noção de limiar de outras semanticamente próximas, tais como as de interstício ou de entre-lugar, muito em voga na retórica do pós-modernismo ou dos estudos pós-coloniais. Diferentemente delas, sua especificidade é a de não depender dos espaços que limita, mas, ao contrário, de questionar a sua legitimidade. Se o limiar é o lugar do anjo, ele revela o que há nele de inassinalável, de irredutível; o anjo é o mensageiro de um mestre invisível, e portanto a única garantia de sua mensagem. "Ou-tópica é a dimensão do Anjo. Seu lugar é a Terra-de-lugar-nenhum [...]. Ninguém saberia indicar o caminho que conduz a ela". ${ }^{*}$ "Mantendo-se no limiar, o anjo proclama sua autonomia e indica-lhe a vocação, no sentido estrito: a possibilidade que uma palavra tem de ofertar ou receber. Seu país é o estrangeiro.

Abraão acreditou que os três anjos fossem viajantes e por essa razão lhes ofereceu a hospitalidade. $\mathrm{O}$ acolhimento do forasteiro estende-se naturalmente à língua estrangeira, sem que se saiba qual das instâncias precede a outra, tanto elas estão ligadas. Paul Ricoeur funda ali sua definição de tradução: "Hospitalidade linguajeira [...] onde o prazer de habitar a língua do outro é compensado pelo prazer de recebê-la na sua, em sua própria morada, a palavra do estrangeiro".* Donde a necessidade da consideração tradutológica de um limiar para toda prática tradutória. Esta tem por função preparar o ambiente propício para acolher o afeto tradutório, aquele que guia a atitude em direção à língua estrangeira: desconfiança ou atração, uma tal ambivalência sendo inerente à natureza do limiar. Portador do desconhecido, o limiar pode suscitar tanto o espanto ${ }^{17}$ como a

\footnotetext{
${ }^{16}$ Em seu livro anterior, Icônes de la loi (Tradução de M. Raiola. Paris: Bourgois, 1990), e mais especificamente no capítulo intitulado "La porte ouverte", Cacciari esboça um pensamento esclarecedor a propósito de nossa concepção de limiar. A imagem do anjo já foi tratada ali.

17 “Sortilège du seuil [Schwellenzauber]”, observa Walter Benjamin quando reúne exemplos do espaço urbano moderno (ver acima): entrada de um apartamento, arco do triunfo, saída de metrô... (BENJAMIN, Walter. Paris, capitale du XIXe siècle. Le livre des passages, op. cit.: 232.)
} 
esperança e ilumina com essa dupla valência o gesto tradutório, que recebe o seu efeito. O limiar decide o que o hostis tem de amigo ou inimigo, as duas faces do estrangeiro:

As testemunhas, note bem, estão de acordo em relação à voz grave [...] Mas quanto à voz aguda, há uma particularidade [...], pois quando um italiano, um inglês, um espanhol e um holandês tentam descrevê-la, cada um se refere a ela como uma voz estrangeira, cada um deles tem certeza de que não é a voz de um compatriota. [...] Uma voz em cujas entonações cidadãos das quatro grandes partes da Europa não puderam identificar nada que lhes fosse familiar! *

É o senhor Dupin, herói de Edgar Allan Poe em Os crimes da rua Morgue, quem apresenta aqui a sua análise. $\mathrm{O}$ que faziam todos esses europeus numa rua parisiense e na cena do crime? Não nos deteremos aí, mas assinalaremos essa voz que ilustra uma estranheza absoluta, resistente a qualquer tradução, voz que mais tarde saberemos pertencer a um orangotango. Talvez o detetive, tal como é encarnado por Dupin, partilhe com o tradutor não o conhecimento do estrangeiro, que, uma vez conhecido, deixa de sê-lo, ${ }^{18}$ mas o conhecimento do que seja o estrangeiro.

Assim, oporei o tradutor-detetive ao tradutor-evangelista. A analogia não é fortuita, em vista do lugar da tradução bíblica na tradutologia ocidental. $\mathrm{O}$ tradutor-evangelista crê em uma verdade no texto. E, seguro dessa convicção, apossa-se do original para arrancá-la dele. Mais ainda, ele vai penetrá-lo quando não se deve penetrá-lo. A imagem, bem sabemos, é de George Steiner em Après Babel.* Conceber a tradução como uma explicação, segundo o paradigma interpretativo (traduzir é compreender), equivale a querer penetrar na obra. Penetração no sentido militar, sem negar as conotações sexuais ligadas à metaforicidade feminina habitualmente aplicada à tradução. Ora, o real da obra reside em sua impenetrabilidade, ou antes, em sua resistência que lhe permite uma recepção e uma interpretação sempre renovada.

Permanecendo em um limiar, sem penetrar no espaço, eu descrevo o que percebo, à distância, ainda que o recebendo em minha interioridade. $\mathrm{O}$ que me permite a seguinte definição: traduzir é descrever em minha língua, com o máximo de precisão possível, o que a outra língua me dá a ver ou a ouvir, o texto primeiro; descrever o que (re)construo como sua significação. Descrever o que

\footnotetext{
${ }^{18}$ A ética de Lévinas nos ensinou que a condição de alteridade se interrompe a partir do momento em que é submetida a um processo de familiarização.
}

* (POE, Edgar Allan. Histoires extraordinaires. C. Baudelaire (trad.). Paris: Le livre de poche, LGF, 1972: 32-33.)

* (STEINER, George, op. cit.: 276-308.) 
* (Ian MacEwan. Atonement. Londres: Vintage Books, 2002: 37.)

* (RANKIN, lan. The Falls Londres: Orion Books, 2008 [2001]: 449.) eu percebo no e a partir do original. Estou ao mesmo tempo na proximidade e na distância do texto a traduzir, e traduzir significa modular o paradoxo. Uma espécie de ekphrasis dentro do mesmo código, na ocorrência do medium verbal. Distância e proximidade. Ian McEwan, identificando a narração a um processo telepático, * convida-nos a compreender a tradução como uma forma de telepatia operando graças ao limiar tradutório: partilhar um pathos à custa de uma distância conquistada.

Proximidade distante ou distância próxima: é o modo como Benjamin define a aura e que sugere a natureza do limiar. $\mathrm{O}$ conceito, central em Benjamin, de semelhança não sensível que desfaz o dogma mimético encontra paralelamente sua ilustração na imagem do limiar e convida a pensar o texto traduzido como recriador do original, sem reproduzi-lo. $\mathrm{O}$ pensamento do limiar invalida as ideologias da equivalência e da fidelidade, pois o limiar é o lugar do desejo do qual se sabe que seu objeto não é autônomo, e sim produzido pela pulsão desejante. Do mesmo modo, o original é produzido pela tradução. Daí a evidência que revela que a tradução não é o original, que ela não pode sê-lo, que ela não deve visar a reproduzi-lo em sua identidade, pois o original é irremediavelmente outro a partir do momento em que é traduzido, uma vez que, justamente, ele não pode ser reproduzido de forma idêntica. A tradução permanece sempre no limiar. E, de lá, faz com que o original exista. Quando John Dryden metaforiza a tradução, ele emprega não a imagem da cópia, mas a do retrato, o retrato do vivente que deve aceitar a sua exterioridade, visando à interioridade.

Se o tradutor pode assemelhar-se ao detetive, é porque este se situa no limiar da verdade. "Working on the edge of things", 19 * escreve Ian Rankin, o criador da série de investigações do detetive escocês de nome tão pertinente, John Rebus. Como nos romances policiais, o que conta é a investigação, não a solução do enigma e a designação do culpado. Proposta provocadora? Certamente, a tradução como produto finito é aquilo que é deixado ao leitor, mas precisamente aquilo que lhe é deixado é uma tradução que não deve ocultar sua natureza, que deve confessar o seu percurso.

Ao preferir o tradutor-detetive ao tradutor-evangelista, não digo (que seja preciso) preferir Maigret a Moisés ou São Jerônimo a Santo Agostinho, mas creio que seja inspirador considerar a tra-

\footnotetext{
${ }^{19}$ No original: "Travailler sur la/en bordure des choses".
} 
dução como uma investigação mais do que como uma busca, seja ela de um sentido ou de uma mensagem. E não me espanta que Umberto Eco tenha batizado Baskerville o herói de $O$ nome da rosa - romance, bem lembremos, apresentado como uma tradução ${ }^{20}$ em menção a um romance de Sherlock Holmes. Aproveitemos a coincidência para homenagear o teórico holandês James S. Holmes, que, nos anos 1970, foi um daqueles que criou os fundamentos batismais para a tradutologia como disciplina.

$\mathrm{Na}$ obra de Poe, o leitor está sempre no limiar da compreensão, mas não pode dar o passo sozinho e deve confiar no detetive para conduzi-lo mais adiante, assim como o leitor de uma tradução deve entregar-se ao tradutor na descoberta da obra estrangeira. O princípio repete-se ao longo da obra, mas principalmente na trilogia dupiniana ${ }^{21}$ que, pelo fato de a ação se passar na França e, portanto, a priori em francês, poderia ser considerada uma tradução - o que torna ainda mais interessante o estudo de sua tradução por Baudelaire.

Lacan explorou o terreno de "A carta roubada", primeiro conto do tríptico, em um célebre seminário. Este último, além de tratar "da maneira como os sujeitos se revezam em seu deslocamento no decorrer da repetição intersubjetiva", ${ }^{*}$ o que define adequadamente a dinâmica tradutória, revela-se uma esplêndida lição de crítica de tradução ao comentar algumas escolhas de Baudelaire, exibindo, ${ }^{*}$ por exemplo, um erro de leitura, e não dos menores: a carta roubada, na tradução, é colocada "em cima do consolo da lareira" em vez de "just beneath [embaixo] the middle of the mantelpiece".

Já evoquei outro consolo de lareira literariamente célebre, o de Alice, e retomo essa narrativa, pois ela nos oferece outra figura instalada num espaço de transição: Humpty Dumpty no muro. Este último faz parte de um trio tradutório que já batizei os três $\mathrm{H}$. Ele inclui Hermes, Hamlet e Humpty Dumpty. O primeiro, deus dos mensageiros, faz o sentido circular por toda parte e sem obstácu-

\footnotetext{
${ }^{20}$ Multitradução, na verdade: "[...] versão italiana de uma obscura versão neogótica francesa de uma edição latina do século XVII de uma obra escrita em latim por um monge alemão por volta do final do século". (ECO, Umberto. Le nom de la rose. J.-N. Schifano (trad.). Paris: Le livre de poche, LGF, 1983: 12.) Nesse sentido, é preciso mencionar também um elemento maior da intriga, o segundo livro da Poética de Aristóteles, que, se fosse encontrado, deveria ser traduzido.

${ }^{21}$ Que tem o nome de seu herói, o cavalheiro C. Auguste Dupin: "La lettre volée", "Le double assassinat dans la rue Morgue", "Le mystère de Marie Roget".
}

* (LACAN, Jacques. "Le séminaire sur La Lettre volée", Écrits I. Paris: Seuil, coll. "Points", 1970: 25.)

* (Ibidem: 47.) 
* (BENJAMIN, Walter. "L'abandon du traducteur", op. cit.: 28.)

* (CELAN, Paul. Choix de poèmes. J-P. Lefebvre (trad.). Paris : Gallimard, 1998: 115.) los; o segundo, príncipe de um reino desfeito, é incapaz de encontrar sentido; e é o terceiro, humano-ovoide, híbrido genérico, quem faz com que o sentido e o não sentido se alternem, empoleirado no alto do muro como no limiar de toda interpretação. Hipersemantização, assemantização e trans-semantização.

Pressinto a objeção: "Humpty Dumpty/ Sat on a wall,/ Humpty Dumpty/ Had a great fall". ${ }^{22}$ Certamente, o perigo espreita. Walter Benjamin já o assinalava a propósito das traduçôes de Hölderlin: "Nelas, o sentido precipita-se de abismo em abismo, até o risco de perder-se no sem-fundo das profundezas da língua".* O risco está ali e o limiar é justamente o lugar do risco: entrar ou não, ameaça ou não, hostis como amigo ou inimigo. É nisso que traduzir não é transcodificar ou comunicar um sentido imutável. A incerteza o acompanha, o que faz da tradução um paradigma pertinente para a epistemologia moderna e contemporânea. Não há passagem direta, e sim respeito pela resistência de cada idioma.

Paul Celan publica em 1955 uma coletânea de poemas intitulada Von Schwelle zu Schwelle, De limiar em limiar. Nela está o poema "Schibboleth", que enuncia precisamente a experiência do limiar. "Schibboleth" é uma palavra hebraica cuja referência provém do episódio bíblico (Juizes, 12: 6) no qual os homens da tribo Galaad identificam os inimigos de Efraim pela incapacidade de pronunciar corretamente o fonema inicial da palavra em questão, na margem do Jordão, outra representação do limiar. Falha de elocução, trata-se também de uma ferida da própria locução, uma vez que os de Galaad, assim como os de Efraim, fazem parte do mesmo povo, falantes da mesma língua. De resto, o termo é associado a outro conflito fratricida, a Guerra de Espanha, figurada pelas menções ao mês de fevereiro, data da tomada do poder pelos republicanos, e de seu grito de adesão: "No pasarán".

Herz:

Gib dich auch hier zu erkennen,

Hier, in der Mitte des Marktes.

Ruf's, das Schibboleth, hinaus

In die Fremde der Heimat:

Februar. No pasarán.* 23

22 "Humpty Dumpty / Sur un mur assis/ Humpty Dumpty /Un 'grand' chute fit" (tradução minha).

${ }^{23} \mathrm{Na}$ tradução de João Barrento: "Coração:/ Dá-te também aqui a conhecer,/ Aqui, no meio da praça./ Chama-o, ao Schibboleth, grita-o/ Para a estranheza da pátria:/ Fevereiro. No pasarán.” 
O último verso do poema ${ }^{24}$ evoca ainda outros acontecimentos históricos de resistência e revolta contra a opressão na Espanha, França e Áustria, quando a história marca a recusa da passagem, do limiar. Um poema de Die Niemandsrose ressalta ainda mais o tema, retomando os mesmos elementos e fazendo alusão ao sangrento fevereiro de 1962 em Paris: "Dreinzehnter Feber. Im Herzmundlerwachtes Schibboleth. Mit dir,/Peuplelde Paris. No pasarán." [Treze de fevereiro. Na boca do coração/ acordado o schibboleth. Contigo,/ Peuple/ de Paris. No pasarán.]*

Aqui, como em outros poemas de Celan, os termos permanecem em língua estrangeira, as palavras não são traduzidas. Não-tradução. Ou a própria experiência da tradução? Mais ainda, talvez, do que se os termos tivessem sido traduzidos. Com essas palavras não traduzidas, o leitor permanece de fato no limiar da língua estrangeira. Como Celan o era diante de sua própria língua e de sua própria história. Por conseguinte, tanto a língua quanto a história precisam ser traduzidas para que sejam partilhadas e transmitidas, sendo impossível o simples dizer. Donde a pertinência atual do limiar para pensar a tradução. Pois, se esta, enquanto símbolo da passagem, pode representar o acolhimento do estrangeiro quando os valores $\mathrm{da}$ hospitalidade e da solidariedade parecem suspensos, é sua posição no limiar que se torna emblemática. No limiar das grandes cidades e metrópoles, os excluídos, os imigrantes ilegais, os refugiados; à margem da Europa, os países ameaçados de falência.

Cinco anos mais tarde, Celan, em seu discurso O Meridiano [Der Meridian], disse do poema que ele "se afirma à beira de si mesmo" [das Gedicht behauptet sich am Rande seiner selbst],* uma postura da qual acaba de fornecer duas ilustraçôes: a poesia como Atemwende, mudança ou inversão do sopro, por um lado, e, por outro, a propensão da poesia contemporânea ao silêncio. Nos dois casos, o escrito deve ser lido no limiar da escritura, ali onde ele não está. Ele recolhe ali uma promessa, um impulso "ins Offene und Leere", ${ }^{*}$ no aberto e no vazio. Celan nomeia também esse lugar "U-topie",* "U-topia”, o traço de união problematizando o conceito, como supra a propósito do quadro de Perugino. Mais ainda, Celan religa a noção às preocupaçõos da poética, ao "estudo dos topoi”,* para concluir lançando mão da imagem que resume sua

\footnotetext{
${ }^{24}$ Analiso-o com mais detalhes em Paul Celan. Les lieux d'un déplacement (pp. 152-153 et 187).
}

* (CELAN, Paul. Die Gedichte. Francfort: Suhrkamp, 2005: 153.)

* (CELAN, Paul. Le Méridien et autres proses. J. Launay (trad.). Paris: Seuil, 2002: 73.$)$

* (Ibidem: 78.)

* (Ibidem: 79.)

* (Ibidem: 79.) 
concepção de caminho poético, o "que retorna a si próprio passando pelos dois polos", ou seja, um meridiano.

Um meridiano transtópico unindo o livro de Santo Agostinho e o de São Jerônimo. É sobre ele que se abre o limiar do traduzir. É ele que o acolhe.

\title{
Tradução de Izabela Leal (UFPA)
}

\begin{abstract}
Alexis Nuselovici (Nouss) é professor na School of European Languages, Translation and Politics da Universidade de Cardiff (Reino-Unido), onde ocupa o posto de Chair of Modern Cultural Studies e é ainda responsável pelo MA Translation Studies. É também professor associado do Departamento de Linguística e de Tradução da Universidade de Montreal, onde atuou durante cerca de quinze anos, tendo sido professor convidado no Brasil, na Turquia, na Espanha e na França. Membro de vários grupos de pesquisa internacionais, criou e dirige em Montreal o grupo de pesquisa "POEXIL" assim como o "Cardiff Research Group on Politics of Translating". Publicou uma dezena de livros entre os quais Plaidoyer pour un monde métis (Paris: Editions Textuel, 2005) e Paul Celan. Les lieux d'un déplacement (Lormont: Éditions Le Bord de l'Eau, 2010). É igualmente tradutor e escreveu os libretos de várias óperas.

E-mail: <NuseloviciA@cardiff.ac.uk>
\end{abstract}

